Supplement of

\title{
Effect of chlorine on water incorporation in magmatic amphibole: experimental constraints with a micro-Raman spectroscopy approach
}

Enrico Cannaò et al.

Correspondence to: Enrico Cannaò (enrico.cannao@unimi.it)

The copyright of individual parts of the supplement might differ from the article licence. 

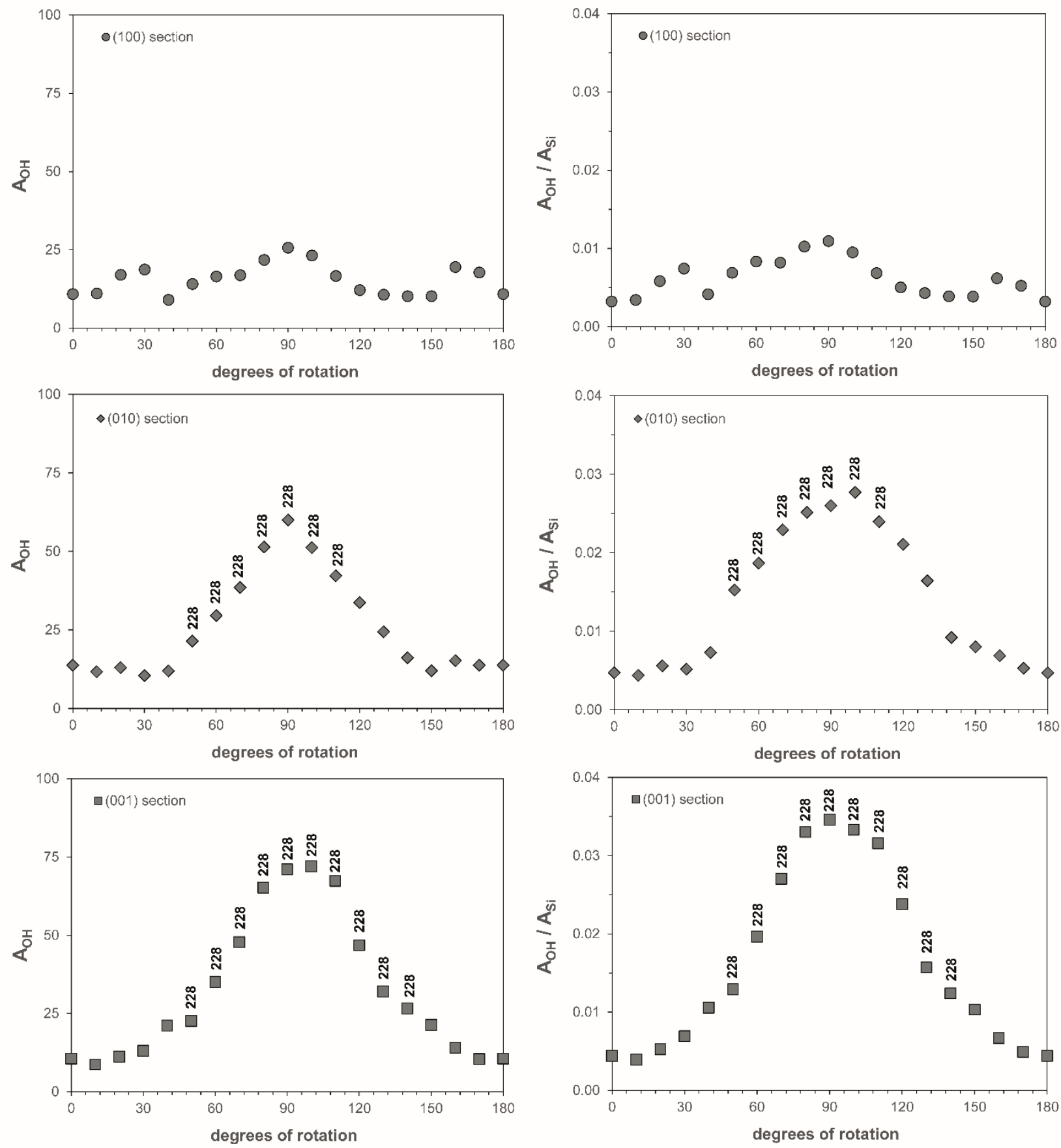

Figure S1. Variations of the area of the $\mathrm{OH}$ band $\left(\mathrm{AoH}_{\mathrm{O}}\right.$ and of the $\mathrm{AoH}_{\mathrm{OH}} / \mathrm{A}_{\mathrm{Si}}$ ratio as a function of the orientation of the kaersutite standard MGT4 relative to the laser beam, for three orthogonal planes. The crystallographic faces of the amphibole were identified under binocular microscope. For (100) and (010) sections, the elongation direction of the crystal is parallel to the polarization direction of the laser beam at $0^{\circ}$, and perpendicular to it at $90^{\circ}$. The spectra with the most intense peak at $228 \mathrm{~cm}^{-1}$ are indicated: the most intense $\mathrm{OH}$ bands are found along this orientation. The remnant spectra show the strongest peak at $750 \mathrm{~cm}^{-1}$. Measurements of the other four kaersutite standards provided analogous figures, but with different absolute intensities. 


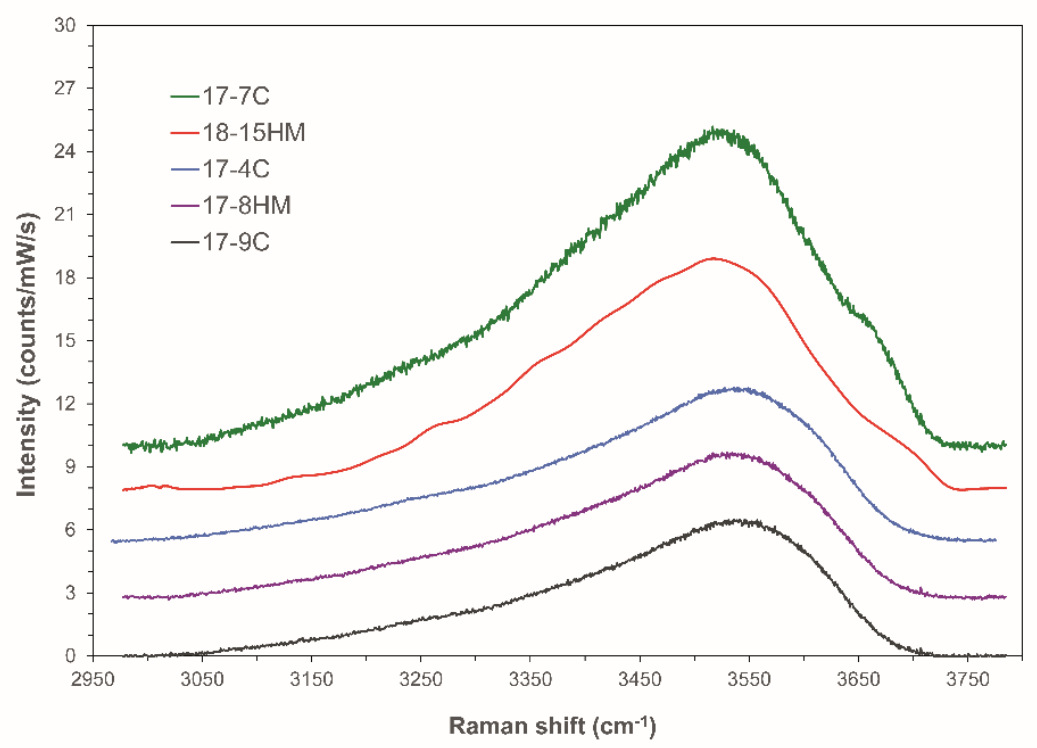

Figure S2. Average spectra in the water region of the glasses in the studied samples. Raman intensity was normalized to laser power and acquisition time. Shown spectra were acquired in standard confocality setting. They are vertically offset for clarity.
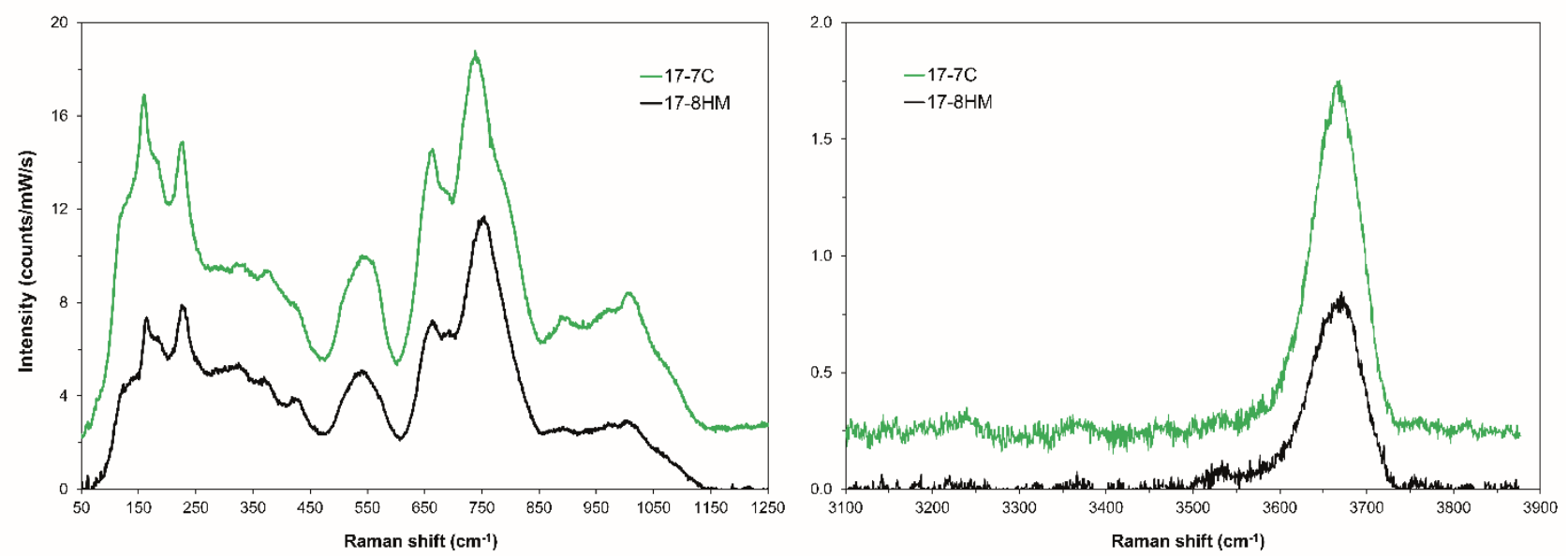

Figure S3. Average polarized spectra in the silicate region (left) and water region (right) of the water-richest amphibole (sample 17-7C) and the water-poorest amphibole (sample 17-8HM). Raman intensity was normalized to laser power and acquisition time. Spectra are vertically offset for clarity. 